\title{
"O que importa é o que acontece com a sua família": um diálogo entre família e migração
}

\section{Resumo}

O cenário das migrações - internas e internacionais - no século 21 tem apresentado mudanças bastante significativas e novos desafios aos pesquisadores. Distâncias mais curtas, mudanças nas expectativas temporais e a composição de trajetórias migratórias mais complexas são algumas das transformações recentes no panorama das novas migrações. Há, no entanto, um ponto de intersecção nessas novas questões: as transformações nos papéis de gênero ao longo dos processos sociais migratórios, fundamentais para que se possa avançar teórica e metodologicamente nos estudos relativos ao fenômeno. É justamente no âmbito da família que essas transformações se expressam de forma mais clara. Neste sentido, este artigo tem como principal objetivo discutir as relações entre os estudos de gênero, família e migrações, buscando novos aportes que ajudem a captar, compreender e avançar em diferentes linhas de pesquisa. O conceito de "trajetórias migratórias" (SÁNCHEZ, 2012) é fundamental para reconstruir os fluxos migratórios desde a sua origem, passando por todas as etapas intermediárias até o local de destino. Além do caminho percorrido pelos migrantes, a recomposição das trajetórias traz à tona as mudanças experimentadas por homens e mulheres ao longo de seus projetos migratórios. Neste sentido, este trabalho contribui para o avanço teórico e metodológico dos estudos de migração.

Palavras-chave: Migração internacional; gênero; família.

\section{Roberta Guimarães Peres}

Doutora em Demografia e Pesquisadora da Universidade Estadual de Campinas - Brasil. roberta@nepo.unicamp.br

\section{Para citar este artigo:}

PERES, Roberta Guimarães. "O que importa é o que acontece com a sua família": um diálogo entre família e migração. Revista PerCursos. Florianópolis, v. 15, n.28, p. 146 - 165. jan./jun. 2014. 


\section{Introdução}

A partir de distintas fases no estabelecimento de um diálogo entre os estudos de gênero e de migração internacional, as relações entre família e trajetórias migratórias compõem uma questão emergente e fundamental. Além dos diferenciais por sexo, é necessário construir um aporte teórico, metodológico e empírico que de fato permita precisar as relações entre migração e família. Parte-se, para tanto, dos lugares de origem e planejamento do projeto migratório, passando pelo cumprimento de suas diversas etapas até o assentamento no lugar de destino. Experiências transnacionais, além da noção de ciclo de vida, constituem o pano de fundo para a reconstrução, negociação e ressignificação da família ao longo de todo o processo social da migração.

\section{Retomando o diálogo entre migrações e relações de gênero}

O objetivo central deste trabalho é contribuir para o debate da incorporação dos estudos de gênero aos estudos de migração internacional e preencher a lacuna resultante da ausência da componente familiar (homens e mulheres) em todo o processo social, e não apenas em seu início (HARBISON, 1981). Neste sentido, parte-se da retomada do diálogo e das intersecções teóricas e metodológicas entre estudos de gênero e migração, buscando identificar o papel da família nas trajetórias migratórias (SANCHEZ, 2012), trazendo à tona a importância da compreensão das transformações dos papéis de homens e mulheres nesses projetos.

Avanços teóricos recentes nos estudos sobre este fenômeno ressaltam a importância de se estudar diferenciais por sexo, transformações nas relações de gênero e também um aporte específico. Segundo Boyd e Grieco:

O gênero está profundamente enraizado na determinação de quem se movimenta, como esses movimentos se dão e quais os impactos nas famílias e mulheres migrantes. Se as teorias de migração internacional integram as relações de gênero de maneira adequada e eficaz, devem levar em conta fatores sutis e óbvios que se misturam para criar diferentes experiências ao longo da migração. A definição e 
compreensão destes fatores melhor fundamentam as teorias de migração internacional e também as experiências individuais de mulheres migrantes em todo o mundo (BOYD; GEIECO, 2003, p. 61)'.

Ao incorporar os diferenciais por sexo às análises de fluxos migratórios, bem como as relações de gênero, indo além da descrição das diferenças entre homens e mulheres, as teorias avançam no sentido de compreender as experiências das mulheres migrantes em esferas específicas - família, domicílio, mercado de trabalho. Segundo Pessar (2000), há importantes intersecções nas transformações dos papéis de gênero, nas estratégias migratórias e na inserção em diferentes mercados de trabalho ao longo do projeto migratório. A interdependência dessas estruturas causa diferentes impactos, principalmente entre as mulheres, mais suscetíveis a essas transformações.

Incorporar as diferentes características de homens e mulheres, bem como utilizar a perspectiva de gênero nas análises, demonstra a importância das diferenças socialmente construídas ao longo da migração. Definidos por Boyd e Grieco (2003) como "sutis", tais fatores referem-se às transformações sofridas sobretudo pela família e ao ganho de autonomia da mulher migrante por sua entrada num mercado de trabalho diferenciado. Segundo Castro:

As diferenças significativas entre os sexos são as diferenças de gênero. Cada sociedade dita o que espera de cada um dos sexos. O status sexual marca a participação de homens e mulheres nas instituições sociais, na família, na escola, na política, na economia, no Estado, nas religiões, incluem valores e expectativas do que uma sociedade espera de ser 0 feminino ou o masculino (BOYD; GEIECO, 2006, p. 66) ${ }^{2}$.

\footnotetext{
${ }^{1}$ "Gender is deeply embedded in determining who moves, how those moves take place, and the result futures of migrant women and families. If international migration theory is to incorporate gender appropriately and effectively, it must take into account the subtle as well as the obvious factors that coalesce to create different experiences all along the migration spectrum. Further defining and understanding these forces and outcomes will greatly enhance theorical grounding of international migration in general and the individual experiences of migrant women around the world"(Tradução livre da autora).

"'Las diferencias significativas entre los sexos son las diferencias de género. Cada sociedad dictamina qué espera de cada uno de los sexos. El status sexual marca la participación de hombres y mujeres en las instituciones sociales, en la familia, la escuela, la política, el Estado y en las religiones, las cuales incluyen valores y expectativas de lo que una sociedad espera del ser femenino o masculino" (Tradução livre da autora).
} 
Num contexto migratório, as diferenças nas relações de gênero são patentes (MOROKVASIC; EREL; SHINOZKI, 2003 e PESSAR, 2000). As transformações experimentadas por ambos os sexos são distintas e cada uma delas tem um impacto diferenciado, especialmente na família e no domicílio. De fato, ao longo do processo migratório, homens e mulheres reconstroem, negociam ou reafirmam relações de poder, hierarquia e a própria identidade (CASTRO, 2006).

Daí a importância de um estudo aprofundado da migração e das transformações de homens e mulheres, especialmente no âmbito da dinâmica familiar. As experiências das mulheres, captadas e analisadas através de uma metodologia específica, oferecem outro sentido ao fenômeno, incrementam e aprofundam seu conhecimento. As lógicas de gênero (KEBABZA, 2004) se expressam, em contextos migratórios, de forma "sutil e íntima". Constrangimentos (como ganho ou perda de autonomia), debate sobre permanência e retorno e renegociações entre os sexos são fatores importantes para o estudo da migração, uma vez que é através dessas transformações que as mulheres, especialmente, se afirmam como agentes de equidade no fenômeno.

É preciso reconhecer, no entanto, a necessidade de uma mudança nas perspectivas teóricas e metodológicas sobre o estudo de família e migração. Esta mudança exigirá, necessariamente, além do olhar voltado às relações de gênero e aos papéis de homens e mulheres em seus lugares de origem, as renegociações e transformações desses papéis ao longo de todo o processo migratório. Para tanto, os estudos de gênero têm contribuído significativamente para a análise de fluxos migratórios, reforçando a ideia de diferentes experiências - masculinas e femininas - na migração, superando a figura assexuada do migrante (HARZIG, 2003), incorporando essas diferenças à seletividade migratória, às motivações para migrar, à composição dos fluxos e à dinâmica familiar. Segundo Castro:

Os marcos conceituais e metodologias de investigação utilizados para o estudo da migração masculina não são adequados para a investigação deste fenômeno em sua contrapartida feminina, já que se reconhece que o ser mulher ou o ser homem incide definitivamente nas motivações, incentivos, limitações e nas possibilidades; isto é, a análise da migração 
feminina ou masculina é atravessada não somente por fatores econômicos, étnicos, de geração, mas também, fundamentalmente, por gênero (CASTRO, 2006, p. 66) $)^{3}$.

Boyd e Grieco (2003) definem os estágios do processo migratório em que a incorporação da perspectiva de gênero é fundamental. O primeiro, o estágio prémigração, inclui fatores como relações de gênero, hierarquia e papéis desempenhados por homens e mulheres no país de origem. O segundo, o cruzamento da fronteira, referese às políticas migratórias dos países de origem e destino - que podem afetar diferentemente a migração de homens e mulheres, determinando estratégias, imagens estereotipadas de ocupações e papéis masculinos e femininos e o potencial de entrada das mulheres no mercado de trabalho receptor. Por fim, o estágio pós-migratório trata do impacto das mulheres num determinado fluxo no mercado de trabalho receptor e no status dos papéis na família e no domicílio.

Papéis desempenhados por homens e mulheres ainda em seus lugares de origem também estão relacionados à perspectiva de gênero no primeiro estágio da migração. Relações hierárquicas nos domicílios, tarefas e ocupações sexualmente definidas, bem como diferentes redes e seus usos afetam tanto a seletividade, quanto as estratégias migratórias utilizadas por homens e mulheres.

Considerando o lugar de destino no estágio pós-migratório, ficam também evidentes os impactos da migração feminina. A dinâmica do mercado de trabalho específico em que se inserem os migrantes pode favorecer a entrada de mulheres, como no caso das bolivianas na fronteira em Corumbá - MS (PERES, 2009), ou de brasileiras que trabalham no setor da faxina nos Estados Unidos (FLEISHER e MARTES, 2003).

Um dos avanços teóricos mais relevantes no campo dos estudos das migrações nos últimos trinta anos é a incorporação da equidade entre homens e mulheres no processo migratório (MOROKVASIC;EREL, 2003). As experiências dos migrantes - sociais,

\footnotetext{
3“Los marcos conceptuales y metodologías de investigación utilizados para el estudio de la migración masculina no son adecuados para la investigación de este fenómeno en su contraparte femenina, ya que se reconoce que el ser mujer o el ser hombre incide definitivamente en las motivaciones, los incentivos, las limitaciones y las posibilidades, es decir, el análisis de la migración femenina o masculina está atravesada no sólo por factores económicos, étnicos, generacionales, sino fundamentalmente por el género"(Tradução livre da autora).
} 
políticas, econômicas e culturais - apresentam diferenciais por sexo, resultando em relações de gênero reconstruídas ao longo das trajetórias que precisam ser levadas em consideração.

Encarar as mulheres como agentes secundários de processos migratórios, invisíveis em suas especificidades, implica ignorar complexidades e heterogeneidades. "O atual contexto dos fenômenos migratórios obriga à construção de novos olhares e perspectivas" (MOROKVASIC; EREL; SHINOZAKI, 2003, p. 15).

Os estudos migratórios sobre o primeiro foco nas mulheres migrantes trouxeram à tona os diferenciais por sexo antes ignorados. As diferentes motivações para migrar, as estratégias, o uso de redes sociais e a inserção na sociedade de destino constituíram informações sobre homens e mulheres a serem processadas separadamente, o que também forçou mudanças no campo metodológico. A dificuldade em se obter dados desagregados por sexo foi uma dificuldade a ser superada.

Os primeiros estudos com este enfoque buscaram, então, "compensar" a ausência das mulheres nas análises desses processos. Desta forma, a tendência foi substituir relações de gênero pela análise dos diferenciais por sexo em fluxos migratórios. Era preciso, no entanto, superar esta fase compensatória e aprofundar as análises para compreender as transformações nos papéis e relações de gênero ao longo da migração. Segundo Morokvasic e Erel:

Analisar a migração sob a perspectiva de gênero não significa apenas que as mulheres devem ser acrescentadas onde estavam faltando. Esta perspectiva exige o olhar para processos e discursos na migração envolvendo mulheres e homens e suas relações entre si no domicílio, na comunidade em que estão inseridos e nas relações internacionais (MOROKVASIC; EREL; SHINOZAKI, 2003, p. 11) ${ }^{4}$.

É preciso reconhecer, no entanto, que o primeiro passo para uma análise sob a perspectiva de gênero é o estudo dos diferenciais entre homens e mulheres ao longo do

\footnotetext{
4 "Gendering migration does not only mean that one should be adding women where they are missing. It means looking at processes and discourses in migrations involving women and men and their relations to one another in household level, in the local community and international relations"(Tradução livre da autora).
} 
processo migratório, trazendo à tona a equidade entre os agentes na migração e não somente colocando a mulher migrante no papel secundário de acompanhante ou, ainda, no da reunificação familiar.

Após esse primeiro momento, em que se fez fundamental desconstruir a figura do homem provedor ("male breadwinner") em contextos em que homens e mulheres se arriscam paralelamente em projetos migratórios (HARZIG, 2003), propõe-se o estudo da migração à luz das transformações sofridas por eles e elas ao longo do processo migratório, tendo relações de gênero como pano de fundo. Neste sentido, a família surge como o lugar principal da renegociação de papéis, de ressignificação dos projetos migratórios e de transformação nas trajetórias de homens e mulheres.

\section{Família e migração: um debate necessário}

Se homens e mulheres têm diferentes experiências ao longo de suas trajetórias migratórias, se têm diferentes acessos a redes sociais de apoio, se passam por diferentes processos de seletividade migratória, se renegociam relações e papéis, é no âmbito da família que se podem observar com mais clareza essas transformações (PESSAR, 2000). A estrutura hierárquica - geracional, etária, sexual - que se observa dentro dos domicílios com experiências migratórias (tanto na origem quanto no destino) e suas transformações ao longo desta experiência evidenciam a necessidade da incorporação da família aos estudos de migração.

No caso de fluxos migratórios, compreender a dinâmica familiar se torna um desafio ainda mais complexo. As experiências transnacionais - não somente restritas aos que migram, mas também aos que permanecem (SÁNCHEZ, 2012) - tornam ainda mais complexa esta análise, uma vez que, em diferentes espaços e ao mesmo tempo, os indivíduos reconstroem permanentemente as suas relações.

Segundo Mummert (2012, p. 151), compreender as dinâmicas familiares em suas formas rotineiras e cotidianas é "como fotografar um alvo em movimento", uma vez que as famílias se transformam continuamente. Segundo a autora, este estado permanente 
de efervescência é ainda mais evidente quando se trata de famílias envolvidas em processos migratórios:

Em processos migratórios internacionais, saem do foco da lente da câmera tanto os membros que se movimentam fisicamente através de fronteiras político-administrativas como seus parentes, que aparentemente permanecem imóveis (MUMMERT, 2012, p. 151) ${ }^{5}$.

Os estudos migratórios têm contemplado a questão da dinâmica familiar, focando sobretudo os lugares de origem dos migrantes. De que maneira a decisão de migrar estaria ligada à posição do indivíduo dentro da família, e de que recursos o domicílio dispõe para promover a migração têm sido as principais inquietações. Segundo Harbison (1981), a estrutura familiar poderia aumentar ou diminuir a probabilidade de migrar. Para o autor, a probabilidade aumenta se uma determinada estrutura reduz o acesso individual a recursos necessários à subsistência. Diminui, se a família cria laços fortes com a comunidade pela redução da disponibilidade, dos motivos e do incentivo para migrar.

Esta visão tem sido bastante criticada nos estudos recentes que estabelecem diálogos entre relações de gênero, família e migrações (ASSIS, 2011; PERES, 2009; PESSAR, 2000; MOROKVASIC, 1984). Uma vez assumida a migração como um processo social - aí compreendidas todas as idas e vindas em suas diferentes etapas -, a família e as relações de gênero se fazem importantes em momentos distintos das trajetórias desse processo, indo além do papel de provedora dos recursos para a viagem ou de controladora da seletividade dos migrantes dentro do domicílio. São muitos os papéis exercidos pela família nas trajetórias dos que migrafam. Neste sentido, as noções "famílias migrantes" ou "famílias de migrantes" se fundem, apontando para as experiências transnacionais, inclusive daqueles que não migraram (SÁNCHEZ, 2012). Segundo Assis:

\footnotetext{
5 “En procesos migratorios internacionales se salen de la mira del lente de la cámara tanto los miembros que se desplazan físicamente a través de fronteras político-administrativas como sus parientes, que aparentemente se quedan inmóviles" (Tradução livre da autora).
} 
As ajudas ocorrem de maneiras variadas: vão desde presentes para os parentes que moram no Brasil, até o cuidado dos filhos que permaneceram no país pelos avós, ou empréstimos para aqueles que ficaram e a administração do dinheiro que os migrantes remetem pelos parentes, ou uma força dos pais no país de destino quando as filhas estão para ganhar seus filhos/as nos Estados Unidos. Esse dar e receber não ocorre sem conflitos, mas o que importa ressaltar é a relevância dessas conexões para o empreendimento migratório (ASSIS, 2011, p. 63).

A perspectiva da família apenas como provedora de recursos nos momentos iniciais das trajetórias migratórias, ainda que supere a visão neoclássica da tomada de decisão,individual e racional,de migrar, não contempla os conflitos e transformações de papéis experimentados pelos migrantes e suas famílias enquanto duram as trajetórias. É a partir dessas transformações que Sánchez (2012) discute a experiência transnacional também dos membros da família que permaneceram nos lugares de origem. Se as experiências transnacionais são definidas pelos vínculos e vivências simultâneos em lugares de origem e destino (CASTLES e MILLER,1998), as diferentes formas de inserção das famílias também proporcionam aos que ficaram essas experiências transnacionais.

O reconhecimento da família como necessariamente unidade de análise para se compreender as dinâmicas migratórias é resultado dos avanços teóricos que tiraram as mulheres da invisibilidade na migração, o que não é um fenômeno novo, uma vez que "é preciso reconhecer que as mulheres sempre migraram" (MOROKVASIC; EREL; SHINOZAKI, 2003; RAVENSTEIN, 1885). Estender o olhar à família e às relações de gênero ao longo do projeto migratório iluminou os estudos de migração no sentido de "reivindicar transformações radicais nos próprios postulados teóricos sobre migrações" (BILAC, 1995).

Se o domicílio é a unidade de análise em que se têm observado as migrações (CUNHA, 2005), o que já representa um avanço em relação à teoria neoclássica, é no âmbito da família e de suas transformações que se poderá aprofundar o conhecimento acerca dos projetos migratórios. Mudanças de papéis, não só de gênero, mas também de gerações, são fundamentais para compreender os pilares que sustentam as trajetórias migratórias: 
As famílias funcionam como unidades de sustentação dos processos migratórios; o padrão, a motivação e as estratégias migratórias são influenciados pelo nível de recursos das residências, pela estrutura de sexo e idade da família, pelos estágios do ciclo de vida familiar (BILAC, 1995, p. 71).

É neste âmbito familiar, e em sua dinâmica ao longo das trajetórias migratórias, que se chama a atenção para as experiências das mulheres. Segundo Castro (1989), a articulação das redes de parentesco, bem como a formação de vínculos entre os membros da família e a criação de redes de apoio mútuo foram habilidades observadas especialmente entre as mulheres.

Mas como captar as transformações ocorridas nas famílias ao longo das trajetórias migratórias? Como acompanhar as renegociações dos papéis de homens e mulheres - da origem ao destino - e as influências na própria dinâmica migratória?

\subsection{Trajetórias migratórias: um desafio metodológico}

Um dos principais debates sobre estudos de fluxos migratórios é constituído justamente pelas fontes de dados a serem utilizadas, suas vantagens e limites. No caso brasileiro, reflexões metodológicas apontam para os censos demográficos como fonte de dados de primeira importância (CARVALHO, 1996) e, ao mesmo tempo, para as lacunas que distanciam o pesquisador da captação de um fluxo migratório, seus processos históricos, mudanças, continuidades e rupturas (SÁNCHEZ, 2012). Segundo Maguid:

É interessante que comecemos a discutir, entre os países da América do Sul, a possibilidade de se criar metodologias inovadoras que nos permitam realmente captar as mudanças que se operam e as que vão ocorrer com relação às características da mobilidade territorial da população em um novo cenário mundial (MAQUID, 1995, p. 194). 
O autor ressalta os censos demográficos como importantes fontes de dados para o estudo do estoque de migrantes - internos e internacionais. O fato de "retratar" um momento específico não permite, no entanto, que só a partir do censo demográfico o pesquisador tenha acesso a todo o processo migratório, do ponto de partida para seu destino no momento da pesquisa.

Segundo Domenach (1996, p. 13), há, entre os estudos de migração, um “estranho paradoxo": ao mesmo tempo em que observamos a maior complexidade e dinâmica dos fluxos migratórios, persiste a análise realizada a partir das mesmas fontes de dados reconhecidamente limitados- e os mesmos conceitos teóricos para interpretar esses movimentos. De acordo com Rigotti(2011, p. 144), "os dados sobre migrações e suas análises refletem e são reflexo do contexto e das tendências da mobilidade espacial da população, além das possibilidades e técnicas de coleta e disseminação".

Se as migrações contemporâneas são marcadas por diferentes etapas migratórias, diferentes motivações para migrar e diferentes fatores de seletividade, apresentam-se então novos desafios aos pesquisadores: a construção de aportes teóricos que possam explicar os movimentos contemporâneos e de aportes metodológicos que superem os limites impostos pelos censos demográficos e possam captar a dinâmica dos fluxos mais recentes. Neste contexto, o desafio metodológico se torna ainda mais complexo, uma vez que as efervescentes dinâmicas familiares transnacionais (SÁNCHEZ, 2012) exigem fontes de dados que acompanhem essas rápidas transformações.

O conceito de trajetória migratória é definido, portanto, como uma ponte entre aportes teóricos e metodológicos. Segundo Sánchez (2012), trata-se de uma ferramenta que pode contribuir para a sistematização da multiespacialidade da experiência migratória e a compreensão de mudanças, continuidades e rupturas no processo histórico da migração.

Ao mesmo tempo, a noção de trajetória permite um recorte analítico da biografia e da experiência migratória, captando as transformações no âmbito familiar e suas relações com diferentes esferas de análise das migrações, como os ciclos de vida, as 
expectativas temporais, a composição das etapas migratórias, o uso estratégico de recursos e as mudanças nos papéis de gênero e geração.

O projeto temático "Observatório das Migrações em São Paulo" (Fapesp/CNPq/Nepo/Unicamp), bem como o projeto “Mulheres migrantes: um debate teórico e metodológico acerca dos estudos de gênero" (CNPq/Nepo/Unicamp) se têm dedicado à reconstrução de trajetórias migratórias e das experiências transnacionais das famílias migrantes. Para tanto, com vistas a superar os limites impostos pela principal fonte de dados de migração, os censos demográficos (CARVALHO, 2004), foi realizada uma pesquisa de campo - intitulada "Trajetórias" - com o principal objetivo de captar as transformações no âmbito da família em contextos migratórios, assim como relacionar diferentes momentos dos fluxos migratórios ao planejamento do ciclo de vida individual sobretudo de mulheres - e da família à entrada no mercado de trabalho nos lugares de destino, ao retorno e à remigração.

A pesquisa, voltada aos fluxos internos e internacionais, contou com a aplicação de 500 questionários no estado de São Paulo ao longo do ano de 2012, a fim de contemplar as diferentes hipóteses dos estudos temáticos que compõem os projetos. Assim, construiu-se o leque da diversidade de fases e faces do espaço migratório paulista (BAENINGER, 2012) desde o fluxo de latino-americanos para a metrópole de São Paulo, até a migração sazonal de piauienses ao interior do estado para a colheita da laranja.

O principal eixo condutor da pesquisa foi a captação das trajetórias migrantes, reunindo informações sobre os migrantes residentes nos domicílios entrevistados e dele ausentes. Assim, puderam-se captar, numa mesma família, experiências migratórias nacionais e internacionais, os impactos das mudanças de papéis entre os que foram es que ficaram, bem como as negociações em diferentes etapas migratórias. A reorientação dos trajetos percorridos por migrantes em função de diferentes etapas do ciclo da vida familiar é uma das principais hipóteses desta pesquisa, que também contou com entrevistas em profundidade para coletar verbalizações que verificassem esta hipótese. As mudanças nos papéis, sobretudo de gênero, que se concretizaram ao longo das trajetórias migratórias, são resultado relevante desta pesquisa. 
Em fase de construção do banco de dados e da análise das entrevistas, a pesquisa “Trajetórias" confirma a hipótese da relação entre o ciclo de vida familiar e o planejamento dos projetos migratórios.

\subsection{Famílias, trajetórias migratórias e ciclo de vida}

As trajetórias migratórias, sempre tratadas em sua dimensão familiar, tanto de quem saiu quanto de quem permaneceu, revelam motivações, transformações sofridas ao longo do processo e, ainda, estratégias para percorrer etapas migratórias distintas e planejá-las em função de outros fatores, especialmente ligados ao ciclo de vida familiar. Segundo Chaves:

Relacionar a migração com os diferentes estágios do ciclo vital - que interfere com maior peso na vida das mulheres, em função dos múltiplos papéis assumidos por elas em certas etapas - se mostrou importante para elucidar aspectos da dimensão familiar e individual da migração (CHAVES, 2000, p. 137).

Trajetórias migratórias não se definem, portanto, apenas pelo percurso completado pelos migrantes em direção a seu destino, até mesmo porque este lugar é muitas vezes redefinido a partir de renegociações de papéis e estratégias no âmbito das famílias. É importante, portanto, apreender o uso estratégico de cada um dos espaços componentes desta trajetória, em suas variadas formas. Segundo Souchaud e Baeninger:

Hoje a migração, em muitos casos, não é um processo linear, mas feita de desvios, retorno, idas e vindas. A multiplicação dos lugares na migração não é aleatória, constitui ou acaba formando uma estratégia, na qual os espaços são considerados como recursos, num processo cumulativo. A circulação dos indivíduos e de bens e informações que lhes são associados, em diferentes espaços articulados entre si, criam uma dinâmica territorial complexa (2008, p. 4). 
Reunindo diferentes dimensões do projeto migratório (MA MUNG, 2009), a noção de trajetória serve aos estudos de migração tanto no que se refere a aspectos teóricos, quanto metodológicos. Segundo Sánchez (2012), construir as trajetórias também implica analisar o tempo da experiência vital individual, especialmente no caso das mulheres. A “experiência vital” se modifica não apenas pela saída de homens e mulheres de seus lugares de origem, mas também pelos diferentes recursos encontrados ao longo das trajetórias e pelas mudanças experimentadas em cada uma das etapas.

Numa das entrevistas em profundidade, realizadas com mulheres bolivianas em São Paulo, as mudanças no âmbito familiar foram descritas pela migrante aqui chamada de Cecília, casada, mãe de dois filhos:

Trabalhar eu sempre trabalhei, a vida inteira. No fim das contas, o que mudou, depois de tantos lugares para onde eu mudei, foi o jeito aqui de casa. Porque o que importa é o que acontece na sua casa, na sua família.

E o que mudou na sua família desde que a senhora saiu da Bolívia?

Quando eu cheguei aqui eu era igual a todas da minha família que ficaram lá. Hoje eu acho que sou diferente. O meu casamento mudou. Eu não vejo tudo e fico quieta como eu ficava antes.

E é isso que faz com que a senhora se sinta diferente?

Claro! Hoje tudo mudou. Eu trabalho o mesmo tanto. Me canso o mesmo tanto, até mais. Posso dar aos meninos as chances que eu não conhecia. E eles também mudaram. O jeito que eles me tratam é diferente do jeito que os filhos tratam lá suas mães e avós. A gente nem importava! Mas o meu marido... esse sim! Foi o que mais mudou. Hoje ele tem que... - como se diz? Hoje ele tem que me engolir!

A trajetória migratória de Cecília foi reconstruída desde a sua saída de La Paz, até a chegada a São Paulo. Com 12 anos, deixou a casa dos pais e foi viver com uma tia em Santa Cruz, para ajudar na criação de seu primo mais novo, e para estudar. Começou a trabalhar no serviço doméstico aos 16. Com 19 anos, voltou para La Paz, onde conheceu o atual marido, residente em El Alto, importante espaço migratório do fluxo de bolivianos para São Paulo (ROLNIK, 2010). Casou-se na Bolívia e logo depois seguiu para São Paulo, 
chegando aos 22 anos. Seu marido, através de uma agência de financiamento, conseguiu um emprego numa oficina de costura no Pari, região central da metrópole. Cecília rapidamente se empregou na mesma oficina e deixou seu posto quando engravidou do primeiro filho.

Eu tinha essa tia, onde eu morei. Eu ajudei com o filho dela e ela me ajudou com o meu. Eu quis voltar porque tinha medo de ir no serviço de saúde, era tudo muito difícil.

Cecília retornou a São Paulo oito meses depois do nascimento do primeiro filho. Não voltou, no entanto, para a oficina de costura, onde seu marido ainda trabalhava. Conseguiu emprego num restaurante peruano na Rua Aurora, no centro de São Paulo, espaço tradicional da presença boliviana e peruana. Ao engravidar do segundo filho, resolveu permanecer em São Paulo. Cecília trouxe então sua mãe para ajudá-la no cuidado com as crianças, já que não tinha um emprego formal e não dispunha de licença maternidade. Segundo ela, foi um momento decisivo na relação com o marido, que foi contra a vinda da sogra. Cecília, trabalhando no restaurante, já ganhava mais que ele e se sentiu com autonomia suficiente para tomar a decisão e trazer a mãe, que ficou em São Paulo por um ano e meio, até conseguirem matricular os filhos na escola. Cecília saiu deste primeiro restaurante e hoje, junto com o marido, prepara refeições em casa, para vender na região da Rua 25 de Março, importante polo comercial de São Paulo, encontro de diferentes fluxos migratórios, especialmente de bolivianos e coreanos.

Hoje, o filho mais velho faz faculdade em La Paz, e mora com os sogros de Cecília. De acordo com seu depoimento, é ele quem administra a casa dos avós, "cumprindo com a obrigação do pai dele, se estivesse lá".

Este discurso de Cecília conta fragmentos de sua trajetória, selecionados especialmente para a análise das transformações nos papéis de gênero e geração observados ao longo do projeto migratório. Através de uma rede de apoio tecida por laços de parentesco, ela cumpre sua primeira etapa migratória, retomando, anos depois, os recursos disponíveis neste ponto de sua trajetória. Retoma, portanto, esta primeira 
etapa, depois de já estabelecida no Brasil, em função do nascimento do primeiro filho. Depois de experimentar uma nova inserção no mercado de trabalho em seu lugar de destino e de passar a ser a principal provedora do domicílio, Cecília sente segurança suficiente para permanecer no Brasil e trazer sua mãe, de La Paz, para ajudá-la, contra a vontade do marido. Mais uma etapa migratória se cumpre, então, nesta família transnacional, em função do planejamento do ciclo de vida associado aos recursos disponíveis em diferentes espaços da migração. Cecília revela ainda a mudança de papel geracional experimentada por seu filho mais velho, que cumpre os deveres de seu pai na casa dos avós.

A trajetória que descreve revela as transformações experimentadas por diferentes membros de sua família, tanto dos que migraram, quanto dos que permaneceram. Os projetos migratórios, associados ao ciclo de vida dos migrantes, são reforçados, portanto, como uma questão importante para se compreender os fluxos migratórios, internacionais e internos, além de se captar entradas e saídas de pessoas entre pontos específicos de origem e destino.

\section{Considerações finais: uma agenda de pesquisa}

Depois de retomado o diálogo acerca das relações entre gênero, gerações, família e migração, é importante assinalar que este é um debate recente e deverá, portanto, contar com o empenho de pesquisadores a fim de construir um aporte teórico aos estudos de migração que dê conta de explicar essas transformações em sua dimensão íntima (PESSAR, 2009). Por tudo isso, nestas considerações finais se abrem muito mais agendas de pesquisa do que necessariamente conclusões resultantes deste debate.

A noção de projeto migratório (MA MUNG, 2009), de biografias migratórias e das próprias trajetórias constitui um caminho novo e instigante para os estudos de fluxos migratórios. As motivações dos migrantes (ALMEIDA, 2013), e outros fatores, como a seletividade migratória, ou os mercados de trabalho específicos para homens e mulheres, podem oferecer um novo olhar aos pesquisadores desde a origem dos migrantes. As transformações nos papéis de gênero e geração, bem como as renegociações e 
redefinições dos fluxos no âmbito familiar aprofundam as análises para além do cálculo racional e individual dos migrantes nos lugares de destino. E, por fim, a perspectiva das etapas migratórias e do uso estratégico dos espaços em cada uma delas, as idas e as vindas dos migrantes, os ciclos de vida e as transformações na composição das experiências transnacionais permitem que se vá além da noção de origem e destino, abrindo um leque de conceitos e recursos metodológicos mais amplo, que capte essas transformações e oriente os estudos migratórios com base também na família, nas relações de gênero e de gerações.

\section{Referências}

ALMEIDA, Gisele Maria Ribeiro. Aurevoir, Brésil: um estudo sobre a imigração brasileira na França após 1980. 2013. Tese (Doutorado em Sociologia) - Universidade Estadual de Campinas , Campinas.

ASSIS, Glaucia de Oliveira. De Criciúma para o mundo: rearranjos familiares dos novos migrantes brasileiros. Florianópolis: Editora Mulheres, 2011.

BAENINGER, Rosana. Fases e faces da migração em São Paulo. NEPO: Universidade Estadual de Campinas, 2012.

BILAC, Elisabete Dória. Gênero, família e migrações internacionais. In: SEMINÁRIO DE EMIGRAÇÃO E IMIGRAÇÃO NO BRASIL CONTEMPORÂNEO, São Paulo: Programa de Avaliação e acompanhamento das Migrações Internacionais, 1995.

BOYD, Monica; GRIECO, Elizabeth. Women and migration: incorporation gender into international migration theory. Washington: Migration Policy Institute, 2003.

CARVALHO, José. Alberto. Magno. et al. Uma caracterização dos estrangeiros nascidos em países do Mercosul e Estados Associados residentes no Brasil no ano 2000. In: ANAIS DO CONGRESSO DA ASSOCIAÇÃO LATINO-AMERICANA DE POPULAÇÃO, I, Caxambu, 2004.

CASTELS, Stephen; MILLER, Mark. The Age of Migration. International Population Movements in the modern World. Pallgrave McMillan, Nova lorque, 1998.

CASTRO, Juventina Yolanda Correa. Ahora la mujeres se mandan solas: migración y relaciones de género en una comunidad mexicana transnacional llamada Pie de Gallo. 2006. Tese de Doutorado em Ciências Sociais, Universidad de Granada, Espanha. 
CHAVES, Maria de Fatima Guedes. Mulheres migrantes: senhoras de seus destinos? Uma análise da migração interna feminina no Brasil: 1980/1991. Tese de Doutorado apresentada ao Programa de Pós Graduação em Demografia. Universidade Estadual de Campinas, 2009

DOMENACH, Hervé. De la Migratologie. Revue Européene de Migrations Internationales, v. 12, n. 2, p. 73 a 86, 1996.

FLEISCHER, Soraya. e MARTES, Ana Cristina Braga. Fronteiras cruzadas: etnicidade, gênero e redes sociais. São Paulo: Editora Paz e Terra 2003.

HARBISON. S. F. Family structure and family strategy in migration decision making. In: JONG, S; GARDNER, R. (Eds.). Migration decision making: multidisciplinary approaches to microlevel studies in developed and developing countries. New York: Pergamon, 1981.

HARZIG, Christiane. Immigration policies: a gendered historical comparison. In: MOROKVASIC, M.; EREL, U.; SHINOZAKI, K. (Eds.). Crossing borders and shifting boundaries: v. I. Oplanden: Gender on the move. 2003.

KEBABZA, Horia. Logiques de genre dans des quartiers impopulaires: au croisment de la race et du genre. Migrations-Sociétés, 17, 2005, p. 99-129.

MAGUID, Alicia. Desafios metodológicos e sistemas de informação no Mercosul. In: PATARRA, Neide Lopes. (Coord.). Emigração e imigração internacionais no Brasil contemporâneo. Campinas: FNUAP, 1995, v. 1. MA MUNG. Emmanuel. Le point de vue de I'autonomiedansl'étude dês migrations internationales. In: DUREAU, François.; HILY, Marie Antoinette. (Coord.) Les mondes de la mobilité. Rennes, Press Univertiaire de Rennes, 2009.

MOROKVASIC, Mirjana. La mobilité transnacionale comme resource: le cas des migrants de l'Europe de l'Est. Cultures et Conflits, n.32, p.105-122, 2002.

MOROKVASIC, Mirjana.; EREL, Umut.; SHINOZAKI, Kyoko. (Eds.). Crossing Borders and shifting boundaries. Oplanden, v. I , 2003.

MOROKVASIC, Mirjana. Birds of passage are also women... International Migration Review, v. XVIII, n. 4, p.886-907, 1984.

MOROKVASIC, Mirjana. In and out of the labour market: Immigrant and minority women in Europe. New Community Genderand Migration, v. 19, n. 3, p.459-483, 1993.

MUMMERT, Gail. Pensando las familias transnacionales desde los relatos de vida: análisis longitudinal de la convivencia intergeneracional. In: ARIZA, Marina.; VELASCO, Laura. (Coord.) Métodos Cualitativos y su Aplicación Empírica: por los caminos de la investigación internacional. México, Instituto de Investigaciones Sociales - UNAM, p. 151-184, 2012. 
PERES, Roberta Guimarães. Mulheres na fronteira: a migração de bolivianas para Corumbá-MS. 2009. Tese (Doutorado em Demografia) - Departamento de Demografia da Universidade Estadual de Campinas , Campinas, 2009.

PESSAR, Patricia. The Linkage Between the household and workplace of dominican women. 2009. U.S. International Migration Review, v. XVIII, n. 4, p.1188-1211, 2000.

RAVENSTEIN, Ernest George. The Laws of Migration. Jornal of Statistical Society. Volume $48, n^{\circ} 2,1885$. P. $167-235$.

RIGOTTI, Irineu. Dados Censitários e técnicas de análise das migrações no Brasil: avanços e lacunas. In: CUNHA, José Marcos Pinto. Mobilidade espacial da população. Campinas: NEPO, Unicamp, 2011.

ROLNIK, Iara. Projeto Migratório e espaço: os migrantes bolivianos na Região Metropolitana de São Paulo. 2010. Dissertação (Mestrado em Demografia) - Universidade Estadual de Campinas, 2010

SANCHÉZ, Liliana Rivera. Las Trayectorias en los estudios de migración. In: ARIZA, Marina.; VELASCO, Laura. (Coord.). Métodos cualitativos y su aplicación empírica: por los caminos de la investigación internacional. México. Instituto de Investigaciones Sociales UNAM, p. 455-494 2012.

SOUCHAUD, Sylvain; BAENINGER, Rosana. Collas y Cambas do outro lado da fronteira: aspectos da distribuição diferenciada da imigração boliviana em Corumbá, Mato Grosso do Sul. Revista Brasileira de Estudos de População, nº. 25, v. 2, 2008, p. 271-286. 
"O queimporta é o que acontece com a sua família": um diálogo entre família e migração

Recebido em: 20/03/2014

Aprovado em: 11/06/2014

Universidade do Estado de Santa Catarina - UDESC

Centro de Ciências Humanas e da Educação - FAED

Revista PerCursos

Volume 15 - Número 28 - Ano 2014 revistapercursos@gmail.com 